age, disease duration, comorbidities, family history of a rheumatic disease, ANA, treatment agents and disease activity and quality of life assessment tools.

Results: A total of 863 RA male patients were studied with a mean age of $53.9 \pm 12.5$ years and a mean disease duration $7.3 \pm 5.5$ years. $652(75.6 \%)$ had positive RF and $624(72.3 \%)$ had positive ACPA. $431(50 \%)$ had at least one comorbidity. $640(74.2 \%)$ were on conventional disease modifying agents (cDMARD's) and 223 (25.8\%) were on biologic therapy. 183 (21.2\%) were smokers. After adjustment of other factors, logistic regression showed that smokers were significantly different than non-smokers in terms of a positive ACPA ( $\beta=-$ $1.051, p<0.001$, odds $=4$.019) and a positive RF $(\beta=-0.804, p=0.019$, odds $=2.517)$. Conclusion: Smokers have a higher risk of expressing a positive RF and a positive ACPA in a male population. Smoking should be considered as a possible risk factor for RA and efforts should be done to educate the population to cease smoking to possibly lower that risk.

References:

[1] Benowitz, N.L., 2009. Pharmacology of nicotine: addiction, smoking-induced disease, and therapeutics. Annual review of pharmacology and toxicology, 49, pp.57-71.

[2] Firestein, G.S., 2003. Evolving concepts of rheumatoid arthritis. Nature, 423(6937), p.356.

[3] Heliövaara, M., Aho, K., Aromaa, A., Knekt, P. and Reunanen, A., 1993. Smoking and risk of rheumatoid arthritis. The Journal of rheumatology, 20(11), pp.1830-1835.

[4] Hoy, K. W., 2009. Quantitative Research in Education: A Primer. SAGE. pp. 69-86.

[5] Kerlan-Candon, S., Combe, B., Vincent, R., Clot, J., Pinet, V. and Eliaou, J.F., 2001. HLA-DRB1 gene transcripts in rheumatoid arthritis. Clinical \& Experimental Immunology, 124(1), pp.142-149.

[6] Kuada, J., 2012. Research Methodology: A Project Guide for University Students. Samfundslitteratur. pp. 45-56.

[7] Kumar, R., 2010. Research Methodology: A Step-by-Step Guide for Beginners. SAGE. pp. 148-159.

[8] Masdottir, B., Jonsson, T., Manfreðsdóttir, V., Víkingsson, A., Brekkan, Á. and Valdimarsson, H., 2000. Smoking, rheumatoid factor isotypes and severity of rheumatoid arthritis. Rheumatology, 39(11), pp.1202-1205.

[9] Neuman, W., 2009. Understanding research. Boston: Pearson. pp. 230- 255.

Disclosure of Interests: None declared

DOI: 10.1136/annrheumdis-2020-eular.6388

\section{AB0177 1 RHEUMATOID ARTHRITIS SAUDI DATABASE (RASD): A SINGLE CENTER EXPERIENCE}

R. Hassan ${ }^{1}$, M. Cheikh ${ }^{1}$, H. Almoallim ${ }^{2}$, H. Faruqui ${ }^{1}$, R. Alquraa ${ }^{1}$, A. Eissa ${ }^{1}$, A. Alhazmi ${ }^{3}$, N. Janoudi ${ }^{1}$. Doctor Soliman Fakeeh Hospital, Jeddah, Saudi Arabia; ${ }^{2}$ Umm AlQura University, Makkah, Saudi Arabia; ${ }^{3}$ Alzaidi Chair of Research in Rheumatic Diseases, Makkah, Saudi Arabia

Background: National Registries are essential to direct current practice and design appropriate management strategies ${ }^{1}$. Rheumatoid arthritis (RA) registries in the middle east and north Africa remain scarcely represented ${ }^{2}$.

Objectives: Our objective is to describe the Saudi RA population and to compare the findings to internationally reported data.

Methods: This is a cross sectional, analytical study that was conducted at Doctor Soliman Fakeeh Hospital (DSFH). The study ran from December of 2014 and concluded in December of 2018 using a pool of 433 patients. Inclusion criteria included adults older than 18 years of age who fulfilled the 2010 American College of Rheumatology criteria for diagnosis of $\mathrm{RA}^{3}$. Data were collected from patients and entered in a specially designed program for this registry. They included main demographic details, lag times to final disease diagnosis. Disease Activity Score-28-C Reactive Protein (DAS-28-CRP) was calculated on presentation and on subsequent visits with intervals ranging from three to six months between them. Multiple regression model was used to assess the predictors of disease activity. We charted the lines of medications given, including conventional and biologic disease modifying antirheumatic drugs (DMARDs), following treat to target strategies ${ }^{4}$.

Results: Out of 430 patients, $76.68 \%$ were female, while only $23.32 \%$ were male and the mean age was found to be 49.26 years with $S D \pm 11$.

At initial presentation, $45.5 \%$ had demonstrated active disease (moderate or high disease activity) based on DAS-28-CRP scores while $54.5 \%$ were in remission or low disease activity. Out of the total number of clinic visitors, 330 had regular follow ups for more than 1 year while 103 patients were either irregularly visiting the rheumatology clinic or had lost follow up. The remission rates after 1 year had increased to $79.7 \%$ (263 patients), while 9.7\% (32 patients) had low disease activity and no patients had sustained high disease activity at the end of follow up. It was also found that the female gender, higher Health Assessment Questionnaire-Disability Index (HAQ-DI) and a longer lag1/lag2 period were associated with higher disease activity in our population. Biologic medications had been used by 129 patients (29.7\%) while conventional DMARDs were given to 304 patients $(70.3 \%)$.

Conclusion: We described a population of RA patients in a single center in SA. We detected higher remission rates at one year of follow up. This could be attributed to many factors, including good referral systems and treat to target strategies with easier access to biologic medications.

References:

[1] Singh JA, Saag KG, Bridges SL Jr, Akl EA, Bannuru RR, Sullivan MC Vaysbrot E, McNaughton C, Osani M, Shmerling RH, Curtis JR, Furst DE, Parks D, Kavanaugh A, O'Dell J, King C, Leong A, Matteson EL, Schousboe JT, Drevlow B, Ginsberg S, Grober J, St Clair EW, Tindall E, Miller AS McAlindon T. 2015 American College of Rheumatology Guideline for the Treatment of Rheumatoid Arthritis. Arthritis Rheumatol. 2016 Jan;68(1):1-26.

[2] Smolen, Josef S., et al. "EULAR recommendations for the management of rheumatoid arthritis with synthetic and biological disease-modifying antirheumatic drugs: 2013 update." Annals of the rheumatic diseases 73.3 (2014): 492-509.

[3] Saag KG, Teng GG, Patkar NM, Anuntiyo J, Finney C, Curtis JR, et al. American College of Rheumatology 2008 recommendations for the use of nonbiologic and biologic disease-modifying antirheumatic drugs in rheumatoid arthritis. Arthritis Rheum 2008;59: 762-84.

[4] Hussain W, Noorwali A, Janoudi N. From symptoms to diagnosis: an observational study of the journey of rheumatoid arthritis patients in Saudi Arabia. Oman Med J. 2016;31(1):29.

Disclosure of Interests: Rola Hassan Grant/research support from: Pfizer pharmaceuticals, Mohamed Cheikh Grant/research support from: Pfizer phar maceuticals, Hani Almoallim Grant/research support from: Pfizer pharmaceuticals, Hanan Faruqui Grant/research support from: Pfizer pharmaceuticals Reem AIQuraa Grant/research support from: Pfizer pharmaceuticals, Ayman Eissa Grant/research support from: Pfizer pharmaceuticals, Aous Alhazmi Grant/ research support from: Pfizer pharmaceuticals, Nahid Janoudi Grant/research support from: Pfizer pharmaceuticals

DOI: 10.1136/annrheumdis-2020-eular.4708

\begin{tabular}{l|l}
\hline AB0178 & PERIARTICULAR OSTEOPHYTE FORMATION \\
& PROTECTS AGAINST TOTAL KNEE ARTHROPLASTY IN \\
& RHEUMATOID ARTHRITIS PATIENTS WITH ADVANCED \\
JOINT DAMAGE
\end{tabular}

S. Asai ${ }^{1}$, N. Takahashi ${ }^{1}$, K. Terabe ${ }^{1}$, T. Kojima ${ }^{1}$, N. Ishiguro ${ }^{1} .{ }^{1}$ Nagoya University Graduate School of Medicine, Department of Orthopedic Surgery, Nagoya, Japan

Background: New medications including biologics and aggressive treatment strategies can halt the inflammatory and destructive disease processes in patients with rheumatoid arthritis (RA), and in some cases repair damaged joints. In the process of damaged joint repair, periarticular osteophyte formation might be detected radiographically (1). However, little is known about the clinical and functional role of osteophyte formation in RA joints. Total joint arthroplasty, a common procedure for treating damaged large joints, can serve as a surrogate for the long-term outcome of large joint destruction in patients with RA.

Objectives: To determine the influence of periarticular osteophyte formation on the incidence of total knee arthroplasty (TKA) in patients with RA.

Methods: This retrospective longitudinal study used data from a registry of patients with RA starting biologics. A flow chart summarizing the study design is shown in Figure 1. A total of 130 symptomatic (tender and/or swollen) knee joints in 80 patients were studied with a median follow-up of 12 years. All data were analyzed using the knee joint as the statistical unit of analysis. The cumulative incidences of TKA were estimated using Kaplan-Meier curves, and compared according to the presence or absence of osteophyte on plain anteroposterior radiograph [osteophyte $(+/-)$ ] and the extent of advanced joint damage as defined by Larsen's grading system (0-II vs. III-V).

Results: Baseline characteristics of all subjects included in this study are shown in Table 1. A total of 42 knees underwent TKA during the follow-up period. There was no significant difference in the cumulative incidence of TKA between the osteophyte (+) and osteophyte (-) groups (31\% vs. $34 \%$ at 10 years, $P=0.718$ ) (Fig. 2A). The cumulative incidence of TKA was significantly higher for the Larsen grade III-V group compared to the Larsen grade 0 -II group (56\% vs. $10 \%$ at 10 years, $\mathrm{P}<0.001$ ) (Fig. $2 \mathrm{~B}$ ). While no significant difference was observed in the cumulative incidence of TKA between the osteophyte $(+)$ and osteophyte (-) groups in the Larsen grade 0 -II group ( $9 \%$ vs. $10 \%$ at 10 years, $P=0.774$ ) (Fig. 2C), the cumulative incidence of TKA was significantly lower for the osteophyte $(+)$ group compared to the osteophyte (-) group in the Larsen grade III-V group ( $38 \%$ vs. $74 \%$ at 10 years, $P=0.010$ ) (Fig. 2D). Multivariate analysis using Cox proportional hazards models revealed that older age [hazard ratio (HR): 1.04 
per 1 year, 95\% confidence interval (Cl): 1.01-1.08] and osteophyte formation (HR: $0.39,95 \% \mathrm{Cl}: 0.19-0.79$ ) independently predicted TKA in the Larsen grade III-V group, whereas none of the assessed variables predicted TKA in the Larsen grade 0 -II group

Table 1. Baseline characteristics by presence or absence of osteophyte formation

\begin{tabular}{|c|c|c|c|c|c|c|c|}
\hline \multirow[b]{2}{*}{ Characteristics } & \multicolumn{2}{|r|}{ Total } & \multicolumn{2}{|c|}{ Osteophyte (+) } & \multicolumn{2}{|c|}{ Osteophyte (-) } & \multirow[b]{2}{*}{$P$ value } \\
\hline & & $n=130$ & & $\mathrm{n}=44$ & & $\mathrm{n}=86$ & \\
\hline Age, years & 57 & $(41-63)$ & 59 & $(52-65)$ & 56 & $(39-63)$ & 0.051 \\
\hline Sex, female, n (\%) & 108 & (83) & 40 & (91) & 68 & $(80)$ & 0.137 \\
\hline Body mass index & 21.3 & $(19.0-23.8)$ & 21.3 & $(18.9-24.4)$ & 21.2 & $(19.0-23.7)$ & 0.744 \\
\hline Disease duration, years & 8 & $(3-12)$ & 9 & $(5-18)$ & 7 & $(3-11)$ & 0.007 \\
\hline Larsen grade, n (\%) & & & & & & & $<0.001$ \\
\hline Grade 0-II & 66 & (51) & 11 & (25) & 55 & (64) & \\
\hline Grade III-V & 64 & (59) & 33 & (75) & 31 & (36) & \\
\hline Osteophyte formation, n (\%) & 44 & (34) & - & & - & & - \\
\hline RF or ACPA positive, $n(\%)$ & 85 & (83) & 35 & (90) & 50 & (78) & 0.183 \\
\hline CRP, mg/dl & 3.2 & $(1.5-4.9)$ & 2.9 & $(1.0-4.1)$ & 3.4 & $(1.8-5.2)$ & 0.172 \\
\hline First biologic agent, $n(\%)$ & & & & & & & 1.000 \\
\hline Infliximab & 57 & (44) & 19 & (43) & 38 & (44) & \\
\hline Etanercept & 73 & $(56)$ & 25 & (57) & 48 & $(56)$ & \\
\hline Use of methotrexate, $\mathrm{n}(\%)$ & 98 & (75) & 33 & (75) & 65 & (76) & 1.000 \\
\hline Methotrexate dose, mg/week* & 8 & $(6-10)$ & 8 & $(6-9)$ & 8 & $(6-10)$ & 0.104 \\
\hline Use of glucocorticoids, $\mathrm{n}(\%)$ & 79 & (61) & 22 & (50) & 57 & (66) & 0.088 \\
\hline Glucocorticoid dose, mg/day $\dagger$ & 5.0 & $(5.0-7.5)$ & 5.0 & $(5.0-5.0)$ & 5.0 & $(5.0-7.8)$ & 0.204 \\
\hline
\end{tabular}

Data are presented as median (interquartile range) or number of subjects (percentages). ${ }^{*}$ Median among subjects receiving the drug. †Prednisolone equivalent (mg/day).

Conclusion: Osteophyte formation reduces the incidence of TKA in patients with RA who have advanced joint damage.

References:

[1] Rau R. Clin Exp Rheumatol 2006;24:S-41-4.

\begin{tabular}{|c|c|}
\hline $\begin{array}{l}\text { Started biologic treatment } \\
310 \text { knees, } 155 \text { patients }\end{array}$ & \\
\hline & \multirow{2}{*}{$\begin{array}{l}\text { TKA prior to initiation of biologics: } 41 \text { knees } \\
\text { Asymptomatic knees: } 131 \text { knees }\end{array}$} \\
\hline & \\
\hline $\begin{array}{l}\text { Symptomatic knees } \\
138 \text { knees, } 87 \text { patients }\end{array}$ & \\
\hline & Missing baseline radiographic data: 8 knees \\
\hline $\begin{array}{c}\text { Analyzed } \\
130 \text { knees, } 80 \text { patients }\end{array}$ & \\
\hline
\end{tabular}

Figure 1. Flow chart summarizing the study design.

Disclosure of Interests: Shuji Asai Speakers bureau: AbbVie, Astellas, Bristol-Myers Squibb, Chugai, Daiichi-Sankyo, Eisai, Janssen, Takeda, and UCB Japan, Nobunori Takahashi Speakers bureau: AbbVie, Asahi Kasei, Astellas, Bristol-Myers Squibb, Chugai, Daiichi-Sankyo, Eisai, Eli Lilly, Janssen, Mitsubishi Tanabe, Ono, Pfizer, Takeda, and UCB Japan, KENYA TERABE: None declared, Toshihisa Kojima Grant/research support from: Chugai, Eli Lilly, Astellas, Abbvie, and Novartis, Consultant of: AbbVie, Speakers bureau: AbbVie, Astellas, Bristol-Myers Squibb, Chugai, Daiichi-Sankyo, Eli Lilly, Janssen, Mitsubishi Tanabe, Pfizer, and Takeda, Naoki Ishiguro Grant/research support from: AbbVie, Asahi Kasei, Astellas, Chugai, Daiichi-Sankyo, Eisai, Kaken, Mitsubishi Tanabe, Otsuka, Pfizer, Takeda, and Zimmer Biomet, Consultant of: Ono, Speakers bureau: Astellas, Bristol-Myers Squibb, Daiichi-Sankyo, Eli Lilly, Pfizer, and Taisho Toyama

DOI: 10.1136/annrheumdis-2020-eular.1209

\begin{tabular}{|l|l}
\hline AB0179 & BEYOND DISEASE ACTIVITY, PAIN, “TIME” AND \\
"TIMING" ACCOUNT FOR DISABILITY IN PATIENTS \\
WITH RHEUMATOID ARTHRITIS: RESULTS FROM A \\
REAL-LIFE COHORT
\end{tabular}

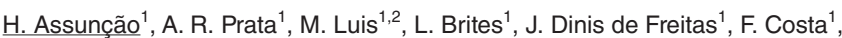
S. Silva ${ }^{1}$, J. A. P. Da Silva ${ }^{1,2}$, C. Duarte ${ }^{1,2} .{ }^{1}$ Rheumatology Department, Centro Hospitalar e Universitário de Coimbra, Coimbra, Portugal; ${ }^{2}$ Institute for Clinical and Biological Research (i.CBR), Faculty of Medicine, Coimbra, Portugal

Background: Patients with rheumatoid arthritis (RA) suffer from joint pain, stiffness and fatigue and are therefore limited in their physical activities. Since
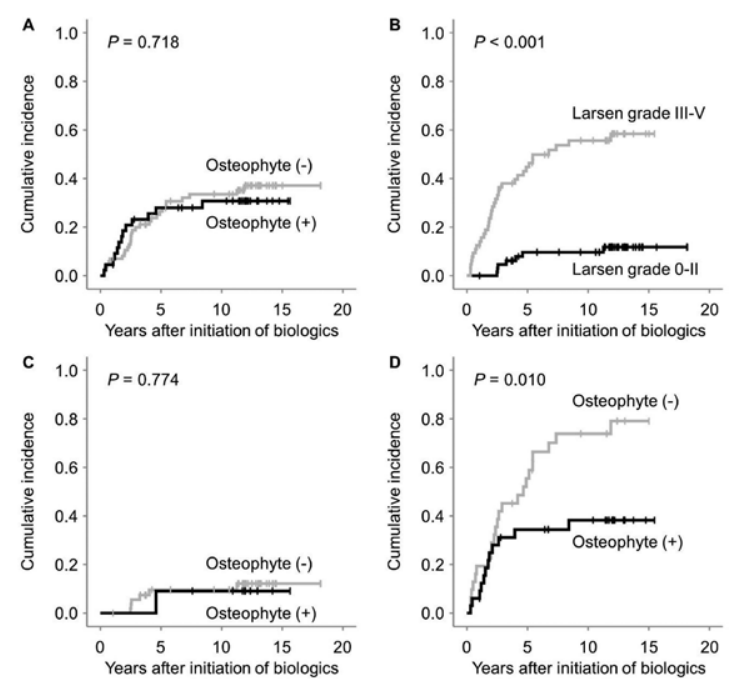

Figure 2. Kaplan-Meier estimates of cumulative incidence of total knee arthroplasty stratified by osteophyte formation (A) and Larsen grade (B) in overall subjects, and by osteophyte formation in the Larsen grade 0-II group (C) and the Larsen grade III-V group (D).

functional disability is a major determinant of quality of life in patients with RA, an optimized approach should focus on the maintenance of functional ability. Objectives: To evaluate self-reported disability in RA patients and to identify its influencing clinical and demographic factors in a real-life cohort of patients with RA Methods: Cross-sectional study of consecutive patients with RA fulfilling the ACR/EULAR 2010 and/or ACR 1987 RA classification criteria, followed in a Portuguese tertiary care centre. Variables collected included socio-demographic and clinical variables (disease duration; time from symptoms onset to diagnosis, classified as short ( $\leq 2$ years) and long ( $>2$ years); time of diagnosis, categorised as <2000, 2000-2009, $\geq 2010$ ); DAS28-CRP-3V and its individual components; pain assessed through visual analogue scale $(0-100 \mathrm{~mm})$ and self-perception of anxiety/ depression through EQ5D dimension 5. Disability was assessed through Health Assessment Questionnaire (HAQ) score and categorised as none-to-mild $(<1)$ or moderate-to-severe (1-3). Comparison between groups was assessed through chi-square or T-student test, as adequate. Variables with $p<0.1$ and others clinically relevant in the researcher's perspective were included in a multivariable logistic regression model. Previously to the analysis, all the assumptions were verified. Given the implementation of new strategies regarding diagnosis and treatment of RA in the last decade, a subgroup analysis was performed for patients with diagnosis performed after 2010).

Results: A total of 251 patients were included $(78.9 \%$ female, aged $62.0 \pm 12.1$ years, disease duration $16.7 \pm 11.2$ years), with a mean DAS28-CRP-3V of 2.24 \pm 0.87 , with $65.3 \%$ being in remission or low disease activity. The mean HAQ score was $1.2 \pm 0.8$. Over half of the patients $(56.2 \%)$ reported moderate-to-severe disability. In the univariate analysis, moderate-to-severe disability was more frequent in female patients $(60.6 \%$ vs $39.6 \%, p<0,006)$, in patients with moderate-to-severe self-perception of anxiety/depressive symptoms $(67.2 \%$ vs $44.2 \%, p<0.001)$ and in patients with diagnosis before the year $2000,2000-2009$ than $\geq 2010(71.4 \%$ vs $63.1 \%$ vs $36.7 \%$; $p<0.001)$. In addition, patients with moderate-to-severe disability tended to be older ( 65.05 vs $57.98, p<0,001)$, to have longer disease duration ( 20.07 vs $12.39, p<0.001$ ), to report more pain (VAS 58.08 vs $28.62, p<0.001$ ) and to have higher disease activity ( 2.48 vs $1.95, p=0.001)$. In the multivariable analysis, pain $(\mathrm{OR}=1.04 ; 95 \% \mathrm{Cl} 1.03-1.06, \mathrm{p}<0.001)$, disease activity $(\mathrm{OR}=1.51 ; 95 \% \mathrm{Cl}$ $1.01-2.26, p=0.049)$, and time of diagnosis $(\mathrm{OR}=0.553,95 \% \mathrm{Cl} 0.38-0.81, \mathrm{p}=0.002)$ remained as independent factors associated with moderate-to-severe disability (R2: $0.40, p<0,001)$. In the subgroup of patients diagnosed after 2010 , a longer time to diagnosis ( $>2$ years) $(\mathrm{OR}=7.97,95 \% \mathrm{Cl} 1.88-34.06 ; \mathrm{p}=0.005)$ and pain $(\mathrm{OR}=1.05$, $95 \% \mathrm{Cl} 1.03-1.08 ; \mathrm{p}<0,001)$ remained as independent factors $(R 2=0.44, p=<0.001)$. Conclusion: Functional disability remains a major problem in our patients with RA, despite clinical remission. Beyond non-modifiable factors, disease activity and pain are associated with higher disability. Moreover, in the subgroup of patients diagnosed after 2010 a long time to diagnosis was the major predictor of disability. However, a large variance of the reported functional disability remains unexplained. Hence, other factors should be properly evaluated in our patients in order to achieve a more holistic approach aiming at reducing functional disability. Disclosure of Interests: Helena Assunção: None declared, Ana Rita Prata: None declared, Mariana Luis: None declared, Luisa Brites: None declared, João Dinis de Freitas: None declared, Flavio Costa: None declared, Stefanie Silva: None declared, José Antonio P. da Silva Grant/research support from: Pfizer, Abbvie, Consultant of: Pfizer, AbbVie, Roche, Lilly, Novartis, Catia Duarte: None declared DOI: 10.1136/annrheumdis-2020-eular.1089 